\title{
Connexin32-Containing Gap Junctions in Schwann Cells at the Internodal Zone of Partial Myelin Compaction and in Schmidt-Lanterman Incisures
}

\author{
Carola Meier, ${ }^{1,2}$ Rolf Dermietzel, ${ }^{1}$ Kimberly G. V. Davidson, ${ }^{2}$ Thomas Yasumura, ${ }^{2}$ and John E. Rash ${ }^{2,3}$ \\ ${ }^{1}$ Department of Neuroanatomy and Molecular Brain Research, Ruhr-University Bochum, 44801 Bochum, Germany, and ${ }^{2}$ Department of Biomedical \\ Sciences and ${ }^{3}$ Program in Molecular, Cellular, and Integrative Neurosciences, Colorado State University, Fort Collins, Colorado 80523
}

\begin{abstract}
In vertebrate peripheral nerves, the insulating myelin sheath is formed by Schwann cells, which generate flattened membrane processes that spiral around axons and form compact myelin by extrusion of cytoplasm and adhesion of apposed intracellular and extracellular membrane surfaces. Cytoplasm remains within the innermost and outermost tongues, in the paranodal loops bordering nodes of Ranvier and in Schmidt-Lanterman incisures. By immunocytochemistry, connexin32 (Cx32) protein has been demonstrated at paranodal loops and Schmidt-Lanterman incisures, and it is widely assumed that gap junctions are present in these locations, thereby providing a direct radial route for transport of ions and metabolites between cytoplasmic myelin layers. This study used freeze-fracture replica immunogold labeling to detect $\mathrm{Cx} 32$ in ultrastructurally defined gap junctions in Schmidt-Lanterman incisures, as well as in a novel location, between the outer two layers of internodal myelin, approximately every micrometer along the entire length of myelin, at the zone between compact myelin and noncompact myelin. Thus, these gap junctions link the partially compacted second layer of myelin to the noncompact outer tongue. Although these gap junctions are unusually small (average, 11 connexon channels), their relative abundance and regular distribution along the zone that is structurally intermediate between compact and noncompact myelin demonstrates the existence of multiple sites for unidirectional or bidirectional transport of water, ions, and small molecules between these two distinct cytoplasmic compartments, possibly to regulate or facilitate myelin compaction or to maintain the transition zone between noncompact and compact myelin.
\end{abstract}

Key words: Charcot-Marie-Tooth disease; connexon; freeze fracture; immunogold labeling; sciatic nerve; tight junction

\section{Introduction}

Myelin, which increases axon conduction velocity in the vertebrate CNS and peripheral nervous system (PNS), is formed by flattened glial cell processes that spiral around axons to form multiple layers of lipid-rich plasma membranes that, in effect, increase axonal membrane resistance and decrease axonal membrane capacitance. In the PNS, myelin is formed by Schwann cells, which ensheathe axons along their entire lengths, except at nodes of Ranvier. Mature myelin consists of "compact" and "noncompact" (or "cytoplasmic") myelin. Noncompact myelin is found at paranodal loops (cytoplasmically expanded lateral margins of Schwann cells bordering nodes of Ranvier), at Schmidt-Lanterman incisures (continuous spirals of stairstepped or overlapping cytoplasmic expansions within areas of

\footnotetext{
Received Nov. 21, 2003; revised Feb. 12, 2004; accepted Feb. 12, 2004.

This work was supported by the Medical Faculty of Ruhr-University Bochum, FoRUM (C.M.), Deutsche Forschungsgemeinschaft Grant De 292/11 (R.D.), and National Institutes of Health Grants NS38121, NS-39040, and NS-44010 (J.E.R.). We thank Hans-Werner Habbes for excellent technical assistance, Helga Schulze for expert illustrations, Klaus Willecke for providing the $\mathrm{X} \times 32$ null-mutant mice used to establish a colony at Colorado State University, and James I. Nagy for Cx29 antibodies provided before publication by Li et al. (2002). We thank Boehringer Ingelheim Fonds for travel grants (C.M.).

Correspondence should be addressed to Dr. C. Meier, Department of Neuroanatomy and Molecular Brain Research, Ruhr-University Bochum MA 6/159, Universitaetsstrasse 150, D-44801 Bochum, Germany. E-mail: carola.meier@ruhr-uni-bochum.de.

DOl:10.1523/JNEUROSCI.5146-03.2004

Copyright $\odot 2004$ Society for Neuroscience $\quad 0270-6474 / 04 / 243186-13 \$ 15.00 / 0$
}

otherwise compact myelin), and at the innermost and outermost cytoplasmic tongues. During initial myelin compaction, the aqueous components of cytoplasm are removed, and the intracellular and extracellular surfaces of the plasma membranes come into close contact, ultimately reducing or eliminating the intracellular and extracellular spaces. One major hypothesis for myelin compaction proposes that cytoplasm is mechanically extruded circumferentially from the advancing outer edge of compact myelin into the adjacent zone of noncompact myelin (Webster, 1971; Bunge et al., 1978) accompanied by tight adhesion of apposed membranes via myelin-specific proteins and cell adhesion molecules (Martini and Schachner, 1997). The existence of the circumferential pathway as the sole mechanism for removal of cytoplasmic constituents, particularly macromolecules, was presumed because, heretofore, there was no evidence for the existence of any type of radial pathway within internodal myelin, except at distant and infrequent Schmidt-Lanterman incisures.

Supplementary to the circumferential pathway proposed for extrusion of cytoplasmic contents during advance of compact myelin, we now provide evidence for an additional structural pathway that is potentially capable of direct radial transfer of ions, water, and small molecules [i.e., through gap junctions that link the cytoplasm of the partially compact (or "semicompact") (Mugnaini et al., 1977) layer to the cytoplasm of the overlying 
cytoplasmic tongue]. As precedent, protein constituents of gap junctions ("connexins") are well documented in peripheral nerve Schwann cells (Bergoffen et al., 1993; Scherer et al., 1995; Yoshimura et al., 1996; Chandross et al., 1996; Mambetisaeva et al., 1999; Nagaoka et al., 1999; Zhao et al., 1999; Altevogt et al., 2002; Li et al., 2002). Immunocytochemical evidence is strong for connexin32 (Cx32) in paranodes, at Schmidt-Lanterman incisures, and along the "inner mesaxon" of the myelin sheath (Bergoffen et al., 1993; Scherer et al., 1995, 1998; Spray and Dermietzel, 1995). As a second precedent, myelin in Cx32-deficient mice and in humans suffering from the related human peripheral neuropathy, X-linked Charcot-Marie-Tooth (CMT-X) disease, which arises from mutations or deletion of the $\mathrm{Cx} 32$ gene, is primarily characterized by degeneration (Bergoffen et al., 1993; Anzini et al., 1997; Scherer et al., 1998). However, particularly in the mouse model, deficiencies in the ultrastructure of compact myelin have been observed also (Anzini et al., 1997).

Dye-transfer experiments performed on peripheral nerves suggest that gap junctions promote direct radial transport between cytoplasmic layers, primarily at Schmidt-Lanterman incisures (Balice-Gordon et al., 1998). Although gap junctions have been reported between myelin layers of paranodal loops in CNS myelin (Sandri et al., 1977), ultrastructurally defined gap junctions have not been demonstrated previously in PNS myelin of mammals. Nevertheless, a few ("less than ten") gap junctions were found between the two outermost myelin lamellae in chicken sciatic nerve, were reported to increase substantially in size and number in internodal regions during Wallerian degeneration, and were presumed to disappear ("no longer seen") during subsequent remyelination (Tetzlaff, 1982). Thus, precedent exists for gap junctions in internodal myelin in PNS, but no role could be assigned on the basis of the rarity of their observation.

Using antibodies to Cx32 and freeze-fracture replica immunogold labeling (FRIL), we now document Cx32 in ultrastructurally defined gap junctions at Schmidt-Lanterman incisures in mice, as well as more abundantly in a novel and unexpected location, between the outer two layers of internodal myelin, throughout the "zone of partially compact myelin" (also called semicompact myelin) (Mugnaini et al., 1977). In addition to radial transport through gap junctions as proposed at SchmidtLanterman incisures (Balice-Gordon et al., 1998), the newly discovered internodal gap junctions provide the structural basis for abundant, closely spaced, short-distance radial pathways, potentially allowing for metabolic communication between the outer two layers of myelin and for transport of water, ions, and small molecules between these two sequential cytoplasmic layers.

\section{Materials and Methods}

Sources of tissue. Immunocytochemical and FRIL analyses were performed on C57/BL6 mice (Charles River Laboratories, Wilmington, MA; Sulzfeld, Germany). Cx32 null-mutants (Cx32-/- females and Cx32 Y/- males) (Nelles et al., 1996) were generated from a colony at the Colorado State University animal facility and established from one breeding pair (kindly provided by Klaus Willecke, University of Bonn, Bonn, Germany).

Immunohistochemistry for light microscopy. For immunocytochemical analyses, 6-month-old mice were deeply anesthetized and decapitated. Sciatic nerves were dissected, the epineuria were removed, and axon bundles were teased onto Superfrost plus glass slides (BDH Laboratory Supplies, London, UK). Samples were fixed in $100 \%$ ethanol $\left(-20^{\circ} \mathrm{C}\right)$ for 15 min and washed in PBS. Nonspecific binding sites were blocked by preincubation in $10 \%$ normal goat serum and $0.1 \%$ Triton X-100 in PBS (blocking solution) for $2 \mathrm{hr}$ at $18-20^{\circ} \mathrm{C}$. Monoclonal Cx32 antibody (Zytomed; Zymed, Berlin, Germany) was diluted 1:200 in blocking solu- tion. Incubation in primary antibody was performed for $16 \mathrm{hr}$ at $18-$ $20^{\circ} \mathrm{C}$. Immunohistochemical analysis on Cx32-deficient tissues, as well as omission of the primary antibody from normal tissues, served as controls for nonspecific binding of primary and secondary antibodies, respectively. Incubation with secondary antibodies (goat anti-mouse, ALEXA 488-conjugated immunoglobulins; Molecular Probes, Leiden, Netherlands) was performed for $2 \mathrm{hr}$ at $18-20^{\circ} \mathrm{C}$. After staining, nerves were mounted in anti-fade mounting medium (Molecular Probes) and photographed using confocal laser scanning microscopy (Zeiss LSM 510 Meta; Zeiss, Göttingen, Germany).

Freeze-fracture immunolabeling. All experiments were conducted according to the National Institutes of Health Principles of Laboratory Animal Care. For most ultrastructural studies, adult mice were anesthetized (90 mg/kg Ketamine, $8 \mathrm{mg} / \mathrm{kg}$ xylazine) and fixed for $10 \mathrm{~min}$ via transcardiac perfusion with $2 \%$ formaldehyde in 0.15 m Sörensen's phosphate buffer (SPB) or were prepared without chemical fixation. (Formaldehyde-fixed tissue was used for samples shown in Fig. 2; all other photographs were from unfixed tissues.) Unfixed and formaldehyde-fixed tissues have different cleaving patterns for some classes of intramembrane particles (IMPs) as compared with the same structures in glutaraldehyde-fixed tissues (e.g., the IMPs in tight junctions) (Staehelin, 1974). However, because of the strong resistance to SDS washing, glutaraldehyde-fixed tissues cannot be used for FRIL (Rash and Yasumura, 1999). Sciatic nerves were dissected, suspended in $10 \%$ gelatin solution, chilled to $4^{\circ} \mathrm{C}$, and cut into 100 to $150 \mu \mathrm{m}$ thick sections using a refrigerated Lancer (St. Louis, MO) 1000 Vibratome. Slices of fixed nerves were infiltrated with $30 \%$ glycerol in SPB, whereas slices of unfixed tissue were infiltrated with $2.5 \mathrm{M}$ sucrose. Cryoprotected slices were frozen by pneumatically damped rapid contact with a $-185^{\circ} \mathrm{C}$ copper mirror (Phillips and Boyne, 1984). Samples were freeze-fractured in a JEOL (Peabody, MA) RFD9010 C freeze-fracture device, coated with $0.5-1 \mathrm{~nm}$ of carbon (Winkler et al., 2002), shadowed with $1 \mathrm{~nm}$ of platinum-carbon, and stabilized with $20 \mathrm{~nm}$ of carbon. Each replicated but unthawed sample was bonded to a gold "index" electron microscope grid in a thin film of 3\% Lexan plastic (GE Plastics, Pittsfield, MA) by evaporating the dichloroethane solvent at $-35^{\circ} \mathrm{C}$ (Rash et al., 1995).

After thawing, cellular material was removed by vigorous washing with SDS detergent (2.5\% SDS in $\mathrm{dH}_{2} \mathrm{O} /$ Tris $\mathrm{HCl}, \mathrm{pH}$ 8.9) for $24-29 \mathrm{hr}$, leaving a thin film of molecules adsorbed to the replica and available for immunogold labeling (Fujimoto, 1995; as modified in Rash and Yasumura, 1999). Before immunolabeling, nonspecific binding sites of the SDS-washed replicas were blocked by preincubation in labeling blocking buffer (LBB) consisting of $10 \%$ heat-inactivated goat serum, $0.5 \%$ teleost gelatin, and 0.05\% sodium azide in $150 \mathrm{~mm}$ SPB (Dinchuk et al., 1987; Rash et al., 1990). Antibodies at a stock concentration of $1 \mathrm{mg} / \mathrm{ml}$ were diluted 1:100 in LBB, either using single antibodies or mixed antibodies of two species. Rabbit polyclonal antibodies to $\mathrm{Cx} 43$ were from Chemicon (Temecula, $\mathrm{CA}$ ), rabbit polyclonal $\mathrm{Cx} 26$ and $\mathrm{Cx} 29$ antibodies, as well as the mouse monoclonal antibodies to $\mathrm{Cx} 32$ and $\mathrm{Cx} 43$, were from Zymed (San Francisco, CA).

Incubation with the primary antibody was performed for $1-1.5 \mathrm{hr}$ at $24^{\circ} \mathrm{C}$. Samples were rinsed in LBB (four times, $10 \mathrm{~min}$ each) and incubated for $12-16 \mathrm{hr}$ at $24^{\circ} \mathrm{C}$ with species-specific secondary antibodies (goat anti-mouse; goat anti-rabbit) coupled to 6, 12, 18, or $20 \mathrm{~nm}$ colloidal gold (Chemicon; Jackson ImmunoResearch, West Grove, PA). Labeled replicas were rinsed in LBB (five times, 10 min each), twice in SPB and three times in distilled water, and were then air-dried. After application of a second "backing" carbon coat on the labeled tissue side of the replica, the Lexan support film was removed by immersing the grid in dichloroethane (six changes in 1-1.5 hr). All samples were viewed in a JEOL 2000 EX-II transmission electron microscope and photographed at $10,000 \times, 30,000 \times$, and $100,000 \times$. Photographic stereopairs were exposed with an $8^{\circ}$ included angle between images and viewed stereoscopically to distinguish specific labeling (occurring on tissue side only) from nonspecific labeling. We showed previously that for samples with low background, $>90 \%$ of nonspecific immunogold beads were on the nontissue, formerly Lexan-coated side of the replica (Rash and Yasumura, 1999). The numerical data presented below were assembled from six replicas from four wild-type mice (one male, three female) single- and double-labeled for $\mathrm{Cx} 32$ (one replica), $\mathrm{Cx} 32+\mathrm{Cx} 29$ (four replicas), and $\mathrm{Cx} 32+\mathrm{Cx} 43$ (one replica). Figures 2, 4, 5A-D, and 6 were derived from 

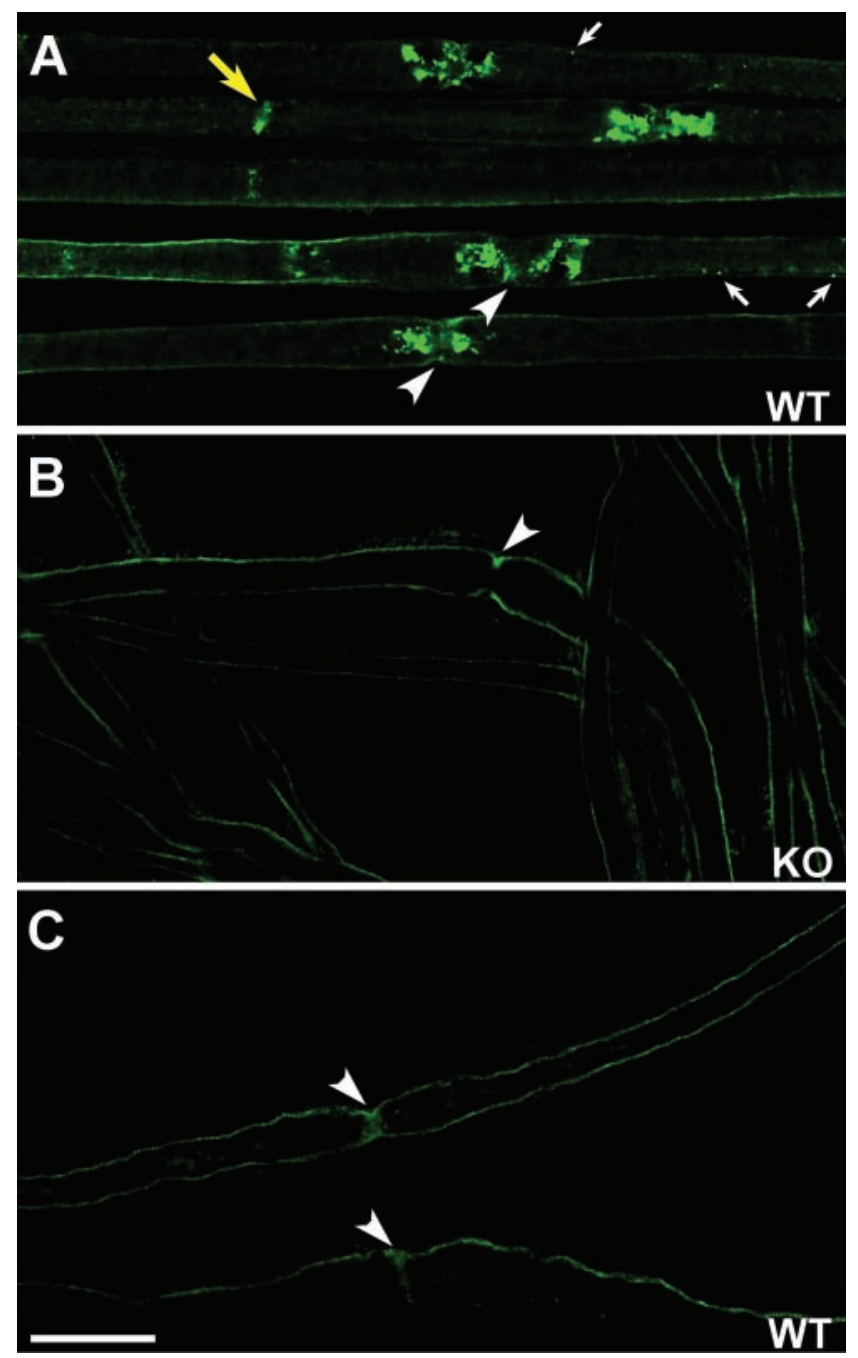

Figure 1. Confocal immunofluorescence images of teased sciatic nerves (composite images of individually teased fibers) after immunolabeling for $(x 32$. $A$, In the sciatic nerve of wild-type mice, immunofluorescence was present at paranodal loops (white arrowheads pointing to nodes of Ranvier) and Schmidt-Lanterman incisures (yellow arrow). Additional fluorescent puncta (white arrows) may also represent discrete immunolabeling along outer layers of myelin, as found by FRIL (Figs. 4 - 6). B, In the sciatic nerve of C $x 32$ null-mutant mice, C $\times 32$ was not detected (white arrowhead at nodes of Ranvier). C, Background immunofluorescence in wildtype mice after omission of monoclonal primary antibody to $C \times 32$ (white arrowheads at nodes of Ranvier). Scale bar, $20 \mu \mathrm{m}$.

replicas from 3-month-old mice, whereas Figure 5, $E$ and $F$, was derived from 5-week-old and 19-month-old animals, respectively. Additional replicas from wild-type mice were double-labeled for $\mathrm{Cx} 26+\mathrm{Cx} 43$ and $\mathrm{Cx} 32+\mathrm{Cx} 43$. Replicas documenting absence of $\mathrm{Cx} 32, \mathrm{Cx} 26, \mathrm{Cx} 29$, and $\mathrm{Cx} 43$ in internodal myelin of Cx32-deficient mice were single-labeled for Cx29 and double-labeled for $\mathrm{Cx} 32+\mathrm{Cx} 43, \mathrm{Cx} 32+\mathrm{Cx} 29$, and $\mathrm{Cx} 26+\mathrm{Cx} 43$.

\section{Results}

\section{Light microscopic immunohistochemistry}

Immunocytochemical analysis of connexin expression in Schwann cells was performed on teased nerve preparations of wild-type and Cx32 null-mutant adult mice. In accordance with previous reports (Bergoffen et al., 1993; Scherer et al., 1995; Spray and Dermietzel, 1995), Cx32 protein was detected immunocytochemically in Schwann cells of wild-type mice using a monoclonal Cx32 antibody (Fig. 1), and this antibody was subsequently used for FRIL analysis. Immunohistochemistry resulted in prominent staining for Cx32 at the site of Schmidt-Lanterman inci- sures and at paranodal loops (Fig. 1A). Occasional punctate immunoreactivity was detected at the outermost Schwann cell surface or the outer mesaxon (Fig. $1 A$, white arrows; also see FRIL images below).

In tests for nonspecific binding of the primary antibody, immunocytochemical labeling for $\mathrm{Cx} 32$ on nerves of $\mathrm{Cx} 32$-deficient mice revealed no detectable immunofluorescence above background (Fig. $1 B$ ). Because omission of the primary antibody revealed no detectable staining within the nerve fibers of wild-type mice (Fig. 1C), nonspecific binding of the secondary antibody at Schmidt-Lanterman incisures or paranodal loops was excluded. However, outer margins of fibers revealed minimal background staining of the secondary antibody (Fig. 1C).

\section{Detection of $\mathrm{Cx} 32$ in gap junctions at Schmidt-Lanterman incisures}

Freeze-fracturing of biological membranes produces either of two views, the protoplasmic leaflet (P-face) or the extraplasmic leaflet (E-face). [The international standard for freeze-fracture nomenclature (Branton et al., 1975) is used in this report.] Freeze-fracture replicas of peripheral nerves reveal membranes from the outermost layer of the Schwann cell to the plasma membrane of the axon, as well as cross-fractured cytoplasm of Schwann cells and axons. Schmidt-Lanterman incisures were rarely fractured to expose their stair-stepped membranes (Fig. 2), and freeze-fractured paranodal loop membranes were not found, presumably because the fracture plane is usually diverted from areas of sharp membrane curvature to nearby membranes with a lower radius of curvature. However, in FRIL replicas labeled for Cx32, immunogold beads drew attention to minute but clearly resolvable gap junctions within Schmidt-Lanterman membranes (Fig. 2C,D). Gap junctions were identified on the basis of their distinctive, hexagonally arranged clusters of $9 \mathrm{~nm}$ IMPs on P-faces (illustrated below) or as clusters of $9 \mathrm{~nm}$ "pits" in membrane E-faces (Fig. 2C,D). The nearby E-face IMPs are not labeled, because they do not correspond to connexin IMPs, which are seen only in replicated P-faces, as shown in Figures $4, C-F$, and $6 A$. Criteria for identifying gap junctions and their constituent connexons in freeze-fracture replicas are reviewed by Rash et al. (1997). [The ultrastructural feature designated as a connexon (Goodenough, 1975) is structurally equivalent to a "hemichannel" (regardless of functional state) and is used to refer to the P-face IMPs, whereas the E-face pits are referred to as "connexon imprints" or "connexon pits." In each case, however, each E-face connexon pit overlies its companion connexon in the unfractured membrane beneath.] Because E-face connexon pits are more difficult to recognize when printed with white shadows, selected images of gap junctions are also printed using the alternative black shadow convention (Fig. $2 C^{\prime}, D^{\prime}$, red overlays), which more closely resemble objects in nature when illuminated with white light (Steere et al., 1980). However, a minor disadvantage of images printed with black shadows is that gold beads appear white.

Although the existence of gap junctions at Schmidt-Lanterman incisures was proposed originally on the basis of light microscopic immunocytochemical data and on dye coupling experiments (Bergoffen et al., 1993; Scherer et al., 1995, Balice-Gordon et al., 1998), these are the first ultrastructural images of gap junctions at Schmidt-Lanterman incisures and the first ultrastructural documentation that $\mathrm{C} \times 32$ is present in these gap junctions. However, in these same replicas, immunogold labels revealed gap junctions in a newly discovered expression site, between the outer two wrappings of internodal myelin at the linear zone corre- 

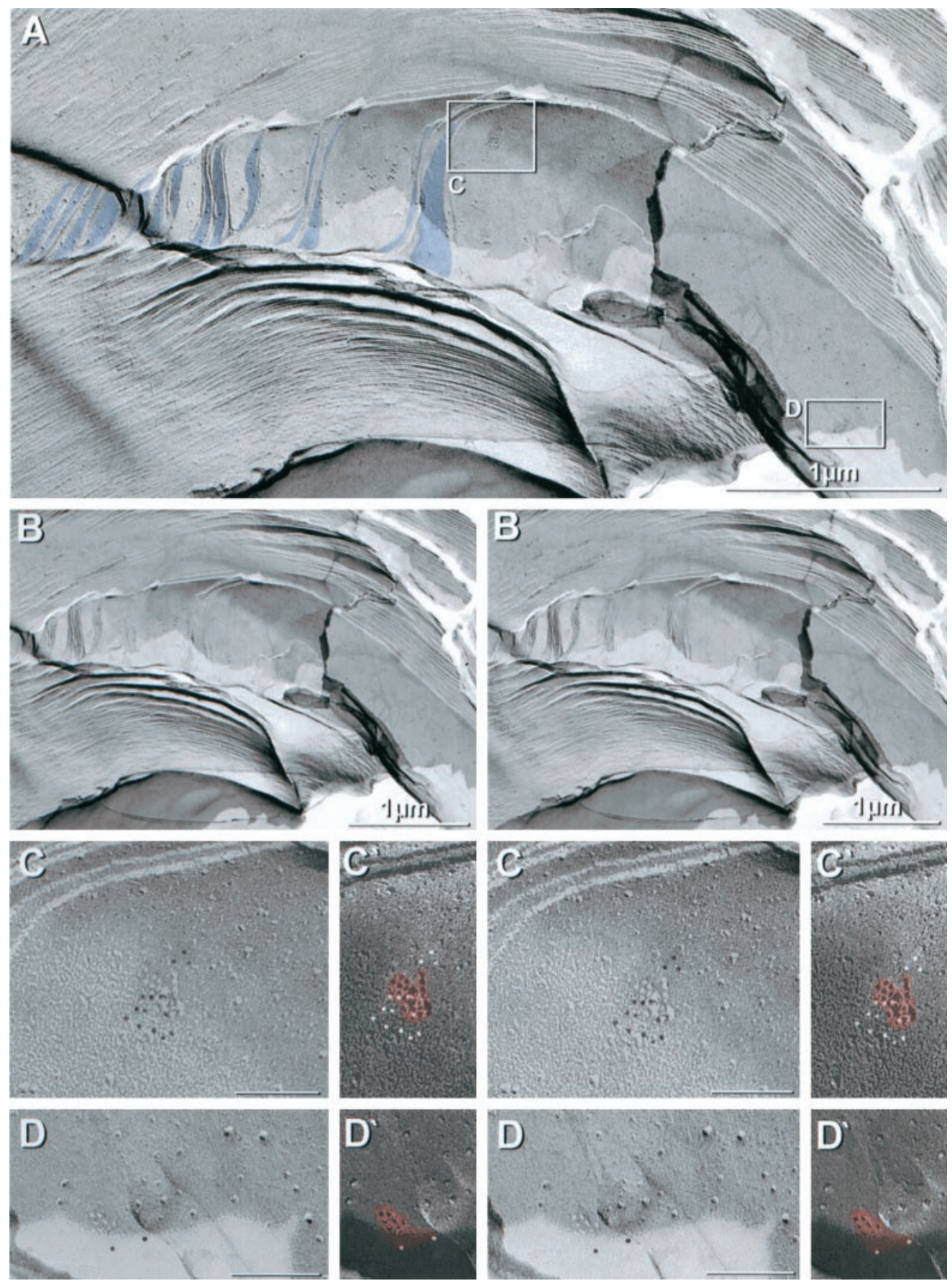

Figure 2. Cx32 immunogold labeling in freeze-fracture replicas of gap junctions in Schmidt-Lanterman incisures. A, Low-magnification view of an extensive stair-step arrangement of cytoplasmic expansions (blue shading) that are characteristic of Schmidt-Lanterman incisures. C, D, The inscribed areas are shown at higher magnification. B, Stereoscopic view of SchmidtLanterman incisures. C, D, High-magnification images of ( $x 32$-labeled E-face gap junctions within the Schmidt-Lanterman incisure. C $\times 32$ is labeled with $6 \mathrm{~nm}$ gold beads. $C^{\prime}, D^{\prime}$, High-magnification views of the same gap junctions, presented with black shadows (i.e., in reversed photographic contrast). At high magnification, white shadows (as seen in $($ and $D$ ) are unnatural and are difficult to interpret by most viewers (Steere et al., 1980). E-face pits of the gap junction are highlighted (red area). Immunogold beads are white in black shadow images. Gold beads smaller than $10 \mathrm{~nm}$ are difficult to detect or discriminate from shadowed IMPs without stereoscopic imaging. Scale bars (in electron micrographs), $0.1 \mu \mathrm{m}$; unless otherwise indicated.

sponding to the area of overlap between the outer cytoplasmic tongue and the next inward layer of partially compacted (or semicompact) myelin. In this study, we characterize their number, size, connexin composition, and subcellular distribution.

Interpretation of freeze-fracture replicas of internodal myelin Interpretation of freeze-fracture replicas is somewhat more complicated for myelin membranes than for membranes of other cell types because: (1) successive layers are closely spaced (without intervening cytoplasm or extracellular space to act as landmarks for identifying fracture faces), (2) the abundance and preferential distributions of IMPs to P-faces (rather than to E-faces) is often replaced by areas in which both $\mathrm{P}$ - and E-faces are devoid of IMPs and pits, and (3) some areas of myelin membrane contain patches consisting of mixed IMPs and pits on both P- and E-faces ("reciprocal patches") (Rash et al., 2001). Although glutaraldehyde fixation more consis- 

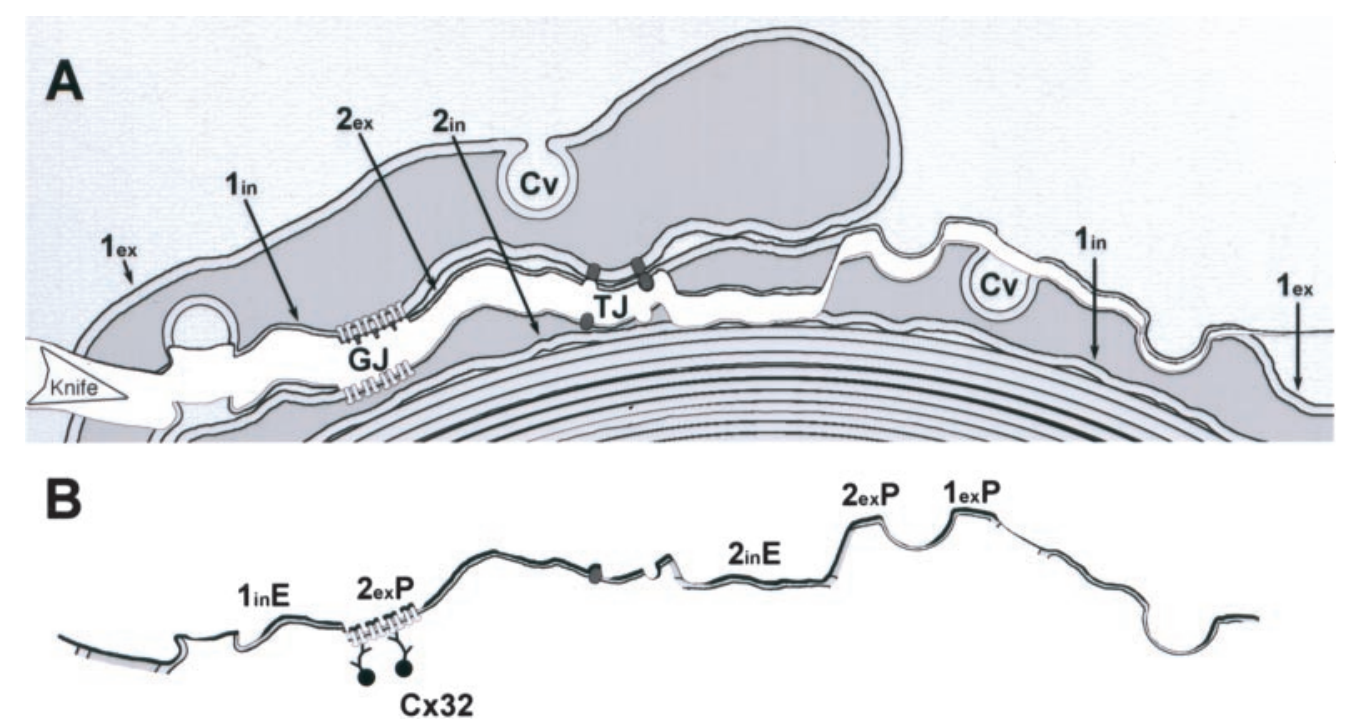

Figure 3. Diagrammatic representation of FRIL images of sciatic nerve, according to the low-magnification image in Figure 4. A, Beginning at the outside, myelin membranes are sequentially designated $1_{\mathrm{ex}}$ and $1_{\text {in }}$ (outer and inner membranes of the outer wrapping of myelin), $2_{\mathrm{ex}}$ and $2_{\text {in }}$ (outer and inner layers of second wrapping), and so on. The fracture plane through a myelinated fiber cross-fractured the cytoplasm (gray) of the outer tongue and then sequentially exposed several membrane faces. Left, The fracture plane first exposed the E-face of the inner plasma membrane of the outer tongue $\left(1_{i n} E\right)$ and then the P-face IMPs of a gap junction (GJ) and IMPs and pits of a tight junction (TJ) linking the inner plasma membrane of the outer tongue to the P-face of the outer plasma membrane of the second wrapping of myelin $\left(2_{\mathrm{ex}} \mathrm{P}\right)$. In the center, the fracture plane exposed the E-face of the inner plasma membrane of the second wrapping of myelin $\left(2_{\text {in }} \mathrm{E}\right)$ and then returned to the P-face of the outer plasma membrane of the first or outermost layer of myelin, which at that point is exposed beyond the tip of the Schwann cell outer tongue. Caveolae (Cv) are cross-fractured and surface-fractured (right margin). B, After SDS washing and immunogold labeling for $\mathrm{C} \times 32$, immunogold beads are found almost exclusively at gap junctions, which are identified as hexagonally packed clusters of $9 \mathrm{~nm}$ P-face IMPs (Fig. 4) or E-face pits (Fig. 50).

tently preserves IMP distributions (Mugnaini et al., 1977), glutaraldehyde-fixed tissues cannot be used in the SDS-FRIL technique (Fujimoto, 1995), because it is based on the use of detergents to remove tissue constituents that are not strongly adsorbed to the replica, and the highly cross-linked proteins in glutaraldehyde-fixed tissues cannot be removed by SDS washing (Rash and Yasumura, 1999).

To facilitate descriptions of myelin layers in freeze-fracture replicas, a numeric system is used (Fig. 3) in which each wrapping of the Schwann cell is numbered from outermost to innermost; each of the two membranes of each cytoplasmic layer is identified as "internal" or "external," and each replicated membrane is then further designated as to fracture face (P-face or E-face). Starting from the external plasma membrane of the outermost layer of myelin $\left[1_{\text {external }}\left(1_{\text {ex }}\right)\right]$ (Fig. 3$)$, the next membrane encountered is the internal membrane of the same outermost uncompacted layer $\left[1_{\text {internal }}\left(1_{\text {in }}\right)\right]$. The next step inward is the outer membrane of the first partially compacted or first completely compacted layer of myelin $\left[2_{\text {external }}\left(2_{\text {ex }}\right)\right]$ followed by its inner membrane $\left[2_{\text {internal }}\left(2_{\text {in }}\right)\right]$. The external and internal membranes of each successive myelin layer are numbered in the same manner. To incorporate information regarding the fracture face of each membrane, the complete designations would be, for example, $1_{e x} \mathrm{P}$, $1_{\text {in }} \mathrm{E}$, or $2_{\mathrm{ex}} \mathrm{E}$, and this convention has been used to label each micrograph.

\section{Freeze-fracture images of the outer layers of myelin}

The outermost layer of myelin-forming Schwann cells is recognized by its apposition to the collagen-filled extracellular space, as well as by the presence of abundant cortical vesicle pits (Fig. $4 \mathrm{~A}$, black arrowheads), which are small cup-like membrane deformations that are characteristic of surface plasma membranes (Mugnaini et al., 1977; Smart et al., 1999). The inner plasma membrane of the same region of each outer tongue (layer $1_{\text {in }}$ ) also contains invaginations consistent with the incorporation of exocytotic vesicles (Fig. $4 A$, white arrowheads). Exocytotic pits represent the sites where cortical vesicles consisting of plasma membrane lipids and proteins fuse with and become incorporated into plasma membranes (Chen and Scheller, 2001). Endocytosis involving clathrin- and caveolin-coated vesicles may also occur, but no attempt was made to differentiate between endocytotic and exocytotic vesicles.

The Schwann cell outer tongue, which is uniformly filled with cytoplasm, is linked to the underlying second layer of myelin by tight junctions (Fig. 4A, white arrows) that run approximately parallel to the long axis of the axon cylinder. Away from the tip of the outer tongue and beyond the band of tight junctions, the remainder of the outer turn is characterized by areas of partially compacted cytoplasm, by reduced or absent cortical vesicle pits, and by the presence of areas resembling partially flattened exocytotic vesicles (Fig. 5A). These flattened invaginations are almost devoid of IMPs. Much of the plasma membrane in the outer turn, particularly near the transition zone to partially compact myelin, contains intermixed particle-free areas in shallow depressions, surrounded by raised areas enriched in small IMPs. Deeper layers of myelin are deficient in cortical vesicle pits and caveolae, and these layers are progressively or completely compacted.

Myelin is one continuous spiral, from the outer mesaxon to the inner mesaxon. Beyond the point where the tip of the outer tongue overlaps the outermost layer, the (formerly) outermost plasma membrane becomes the outer membrane of the second layer of myelin. Thus, the seamless transition of the outermost layer of noncompact myelin (Fig. 4, $1_{\mathrm{ex}} \mathrm{P}$, outlined in green) into its continuation as the second layer of myelin (Fig. 4, $2{ }_{\mathrm{ex}} \mathrm{P}$, green shading) is necessarily indistinct, but nevertheless, is detectable as the area where the density of cortical vesicles is abruptly reduced. In this image, the outer tongue of myelin was removed during fracture, and only a small remnant of the cross-fractured outer tongue is visible (Fig. $4 \mathrm{~A}$, blue shading, top center). However, the edge of its three-dimensional imprint is detectable in stereo- 


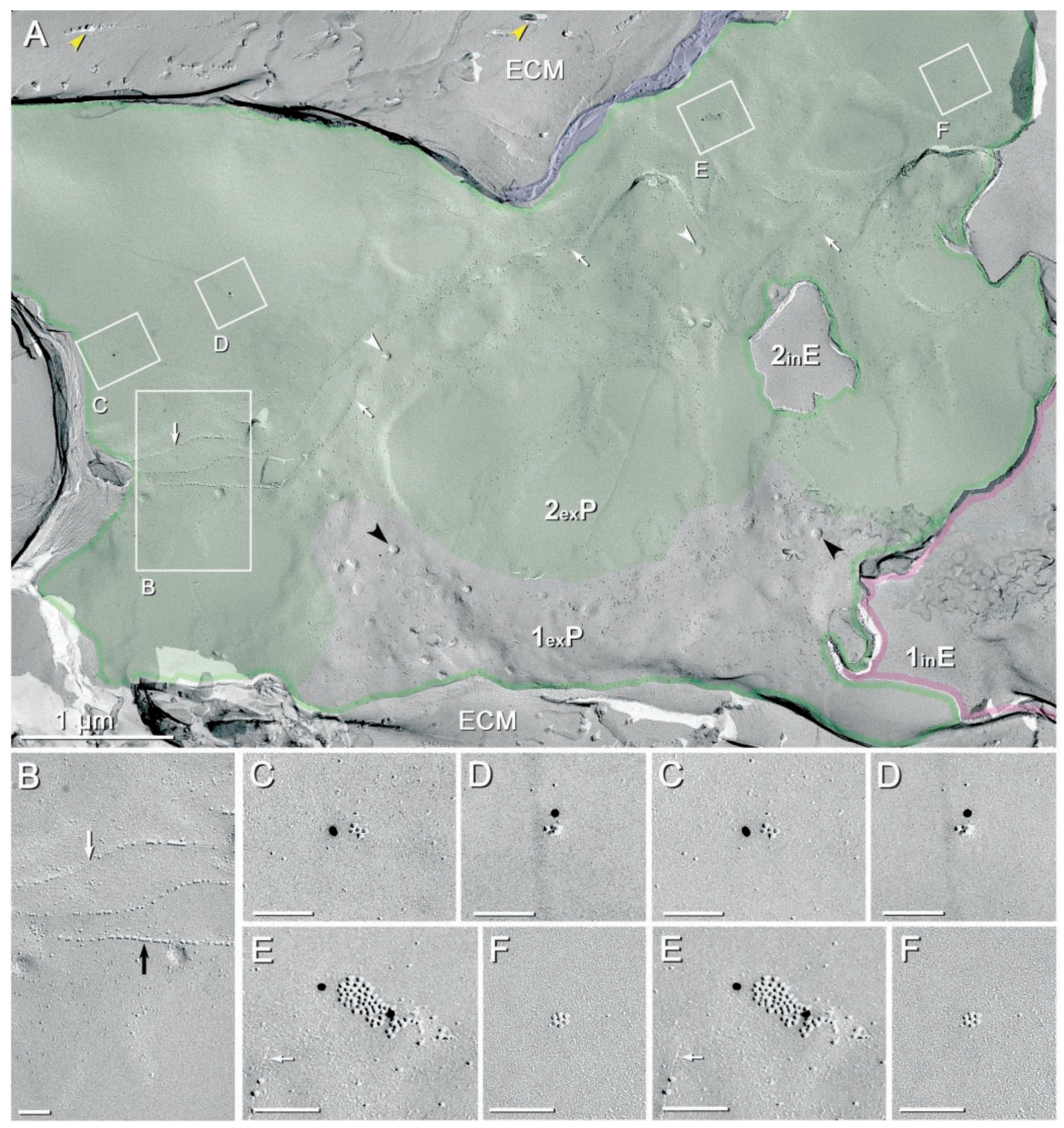

Figure 4. FRIL image of a broad expanse of outer myelin membranes labeled for $\left(x 32\right.$. $A$, The outermost layer of myelin $\left(1_{\mathrm{ex}} \mathrm{P}\right)$ is characterized by abundant caveolae (black arrowheads). The outer tongue has been fractured away, revealing its cross-fractured cytoplasm (blue). Where the outer tongue has been removed by fracturing, the second layer of myelin $(2 \mathrm{ex}$; shaded green) is recognized by the absence or reduced density of caveolae (white arrowheads), lower density of IMPs, or areas devoid of IMPs and having smooth contour. The extracellular matrix (ECM) contains collagen fibers (yellow arrowheads). Tight junctions ( $B$, white arrows) and gap junctions ( $(-F)$ are shown at higher magnification. $B$, Higher magnification view of tight junction strands, with rows of IMPs (black arrow) intermixed with grooves of pits (white arrow), which represent the sites where some of the tight junction particles-proteins were removed by fracturing. $C-F$, Stereoscopic $P$-face images of gap junctions, three of which are labeled for $C \times 32\left(C-E ; 12 \mathrm{~nm}\right.$ gold beads) and one is unlabeled $(F) .1_{\mathrm{ex}} \mathrm{P}, \mathrm{P}$-face of the outer membrane of the outermost (first) Schwann cell wrapping; $1_{\text {in }} E$, E-face of the inner membrane of the outermost $S$ chwann cell wrapping; $2_{\mathrm{ex}} \mathrm{P}, \mathrm{P}$-face of the outer membrane of the second Schwann cell wrapping.

scopic images (data not shown) as a continuous shallow depression of the outer myelin layer, corresponding to the area shaded in green.

Along its entire length, the outer tongue of myelin is linked to the underlying membrane by tight junctions (Mugnaini et al., 1977; Sandri et al., 1977; Peters et al., 1991), binding membranes $1_{\text {in }}$ to $2_{\mathrm{ex}}$ (Fig. $3 A$ ). In areas where the outer tongue of myelin was completely removed by fracturing, tight junctions were seen in myelin layer $2_{\mathrm{ex}} \mathrm{P}$ (Fig. $4 A$, white arrows, $B$ ). These tight junction strands, although located on a P-face, consist of rows of IMPs (Fig. $4 B$, black arrow) intermixed with linear grooves of pits (Fig. $4 B$, white arrow), a mixed morphology that is characteristic of tight junctions in un- 

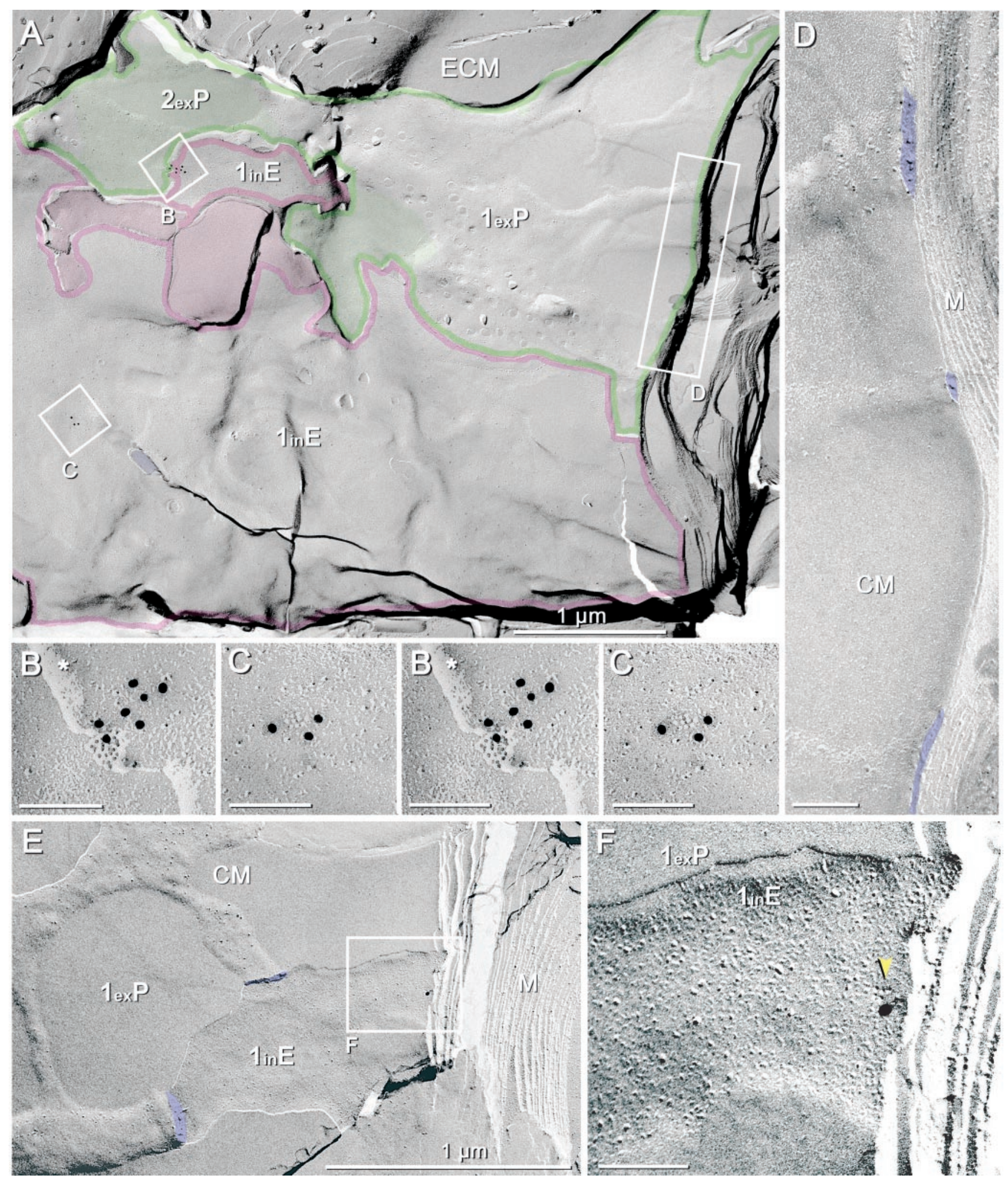

Figure 5. FRIL images of outer myelin layers after immunogold labeling for $\left(X 32 . A\right.$, Low-magnification image of myelin membrane $1_{\mathrm{ex}} \mathrm{P}$, which is characterized by abundant caveolae. $D$, Layer $2_{e x} P$, the outer membrane of the underlying Schwann cell wrapping, is characterized by the presence of rivulets containing residual cytoplasm, as documented at different tilt angle, $5 D$, adjacent. Two gap junctions are visible (inscribed areas $B$ and C. $B, A$ gap junction located where the fracture plane stepped from layer $2_{\text {ex }} P$ to $1_{\text {in }} E$ consists of both $P$-face IMPs and E-face pits. The extracellular space $\left.{ }^{*}\right)$ is narrowed to $<3 \mathrm{~nm}$ within the area of the gap junction. C, Gap junction in membrane $1_{\text {in }} E$. The E-face pits are immunogold labeled for $C \times 32$. D, At a high tilt angle, rivulets at the margin of cross-fractured myelin $(M)$ are seen to contain cytoplasm (blue shading). E, Removal of the top rivulet membrane $\left(1_{\mathrm{ex}} \mathrm{P}\right)$ reveals a view of the E-face of the underlying membrane $1_{\text {in }}$. Gap junctions frequently were found on rivulet membranes (inscribed area $F$ ). $F$, $\left(x 32\right.$ immunogold-labeled gap junction (yellow arrowhead) in particle-rich myelin membrane $2_{\text {in }} E$. ECM, Extracellular matrix; $1_{\text {ex }} P$, $\mathrm{P}$-face of the outer membrane of the outermost Schwann cell wrapping; $1_{\text {in }} \mathrm{E}$, E-face of the inner membrane of the outermost (first) Schwann cell wrapping; $2_{\mathrm{ex}} \mathrm{P}, \mathrm{P}$-face of the outer membrane of the second Schwann cell wrapping. 
fixed and formaldehyde-fixed tissues used for FRIL (see Materials and Methods). Internodal tight junctions run approximately parallel to the long axis of the axons and parallel to the border of continuously compact myelin, except at Schmidt-Lanterman incisures, where they follow the Schmidt-Lanterman incisure internally (Mugnaini et al., 1977). In young adult mice, the first layer of continuously compact myelin usually occurs in the second or third turn. With tight junctions along one side and the border of compact myelin along the other side, these two diffusion barriers create an isolated osmotic compartment in the extracellular space between the outer two wrappings of myelin.

\section{Cx32 labeling of gap junctions in internodal myelin}

In Figure $4 A$, a total of four immunogold beads are visible on layer $2_{\mathrm{ex}} \mathrm{P}$. At higher magnification, the gold beads were seen associated with three of four distinctive clusters of closely spaced, hexagonally arranged $9 \mathrm{~nm}$ IMPs (Fig. $4 C-E$ ). All other areas were essentially devoid of clusters of large-diameter IMPs and of gold labels. On the basis of their close association with Cx32immunogold beads, as well as on low nonspecific background seen elsewhere, these distinctive hexagonal arrays of $9 \mathrm{~nm} \mathrm{P}$-face IMPs were identified as gap junctions. Thus, as in other tissues, gap junction IMPs are clearly distinguishable from most other IMPs by their uniform larger diameter and regular hexagonal close packing (Fig. 4A,C-F). However, the gap junctions in this photograph are surprisingly small, ranging from 4 to 52 particles. Also within this patch of membrane, in approximate alignment with the labeled gap junctions is one unlabeled hexagonal cluster of seven IMPs (Fig. 4A,F), also identified on morphological grounds as a gap junction. On the basis of the observed labeling efficiency (see below), $\sim 10 \%$ of gap junctions containing 10 IMPs would be expected to be unlabeled.

The four gap junctions seen in Figure 4, located on the same small area of layer $2_{\mathrm{ex}} \mathrm{P}$, have relatively regular spacings of $\sim 1 \mu \mathrm{m}$ (occasionally up to $4 \mu \mathrm{m}$ ) between junctions. This pattern of small, closely spaced gap junctions was repeated throughout the length of internodal myelin (see numerical data below). As many as seven gap junctions were seen in a single membrane patch along the boundary between noncompact and partially compact myelin, and in most cases, these were also separated by $\sim 1 \mu \mathrm{m}$. Therefore, we calculated that there were 500-1000 gap junctions per millimeter of internodal myelin. The locations and structural interrelationships of tight junctions, gap junctions, caveolae, and cytoplasmic rivulets are illustrated in Figure 3.

The color scheme introduced in Figure 4 is applied in Figure 5 also. The outermost myelin membrane (layer $1_{e x} \mathrm{P}$ ) is outlined in green, and the green shading designates its continuation where the outermost myelin tongue had advanced over it, thereby converting the extension of layer $1_{e x} \mathrm{P}$ into layer $2_{\mathrm{ex}} \mathrm{P}$. This image also illustrates a different view of the membranes of the outer tongue (i.e., the E-face of its inner plasma membrane) (Fig. 5, layer $1_{\text {in }} \mathrm{E}$, outlined in red). As noted above, cortical vesicle pits are abundant in the outermost Schwann cell plasma membrane (layer $1_{e x} \mathrm{P}$, outlined in green), as well as in the inner membrane of the outer tongue (layer $1_{\text {in }} \mathrm{E}$, outlined in pink). Immunogold beads indicating Cx32 labeling are present at several locations (Fig. $5 B, C)$. These gold beads mark two gap junctions, one of which includes the step from E- to P-face within the margin of the gap junction (Fig. $5 B$ ). In such images, the narrowing of the extracellular space within the border of the gap junction (Fig. $5 B$, asterisk) provided a fourth distinctive feature for identifying gap junctions [criteria listed by Rash et al. (1997, 1998)]. Thus, for gap junctions between layers $1_{\text {in }}$ and $2_{\text {ex }}$, four freeze-fracture views are possible $\left(1_{\text {in }} \mathrm{P}, 1_{\text {in }} \mathrm{E}, 2_{\mathrm{ex}} \mathrm{P}\right.$, and $\left.2_{\mathrm{ex}} \mathrm{E}\right)$, with two of those views seen simultaneously where the fracture plane steps from one membrane face to the other within the gap junction (for example, $1_{\text {in }}$ E to 2 ex $\mathrm{P}$ ) (Fig. $5 B$ ).

\section{Structural components defining the zone of partially compact myelin}

In areas of partially compact myelin, which occur within the outer few wrappings of internodal myelin, distinctive membrane $\mathrm{P}$-face ridges and E-face furrows were observed (Fig. 5A,D). Although these furrows and ridges were described previously (Mugnaini et al., 1977; Sandri et al., 1977), neither group characterized them further. However, when traced to the edge where myelin is cross-fractured, cytoplasm was always found between the P-face ridges and the E-face furrows (Fig. $5 D$, blue areas). Because freeze-fractured membranes of deeper layers of compact myelin consist primarily of large areas that are essentially devoid of IMPs, and the IMPs in the remaining patches of membrane are primarily $<6 \mathrm{~nm}$ in diameter, and because these areas enclose little or no cytoplasm, the cytoplasmic rivulets gain particular importance in that they represent areas of residual cytoplasm within areas of partially compact myelin. Cx32-labeled gap junctions were frequently found on such membrane ridges overlying cytoplasmic rivulets. In areas where the rivulet $\mathrm{P}$-face membrane was removed over an area of underlying cytoplasm, the imprint of cytoplasm was also evident in the E-face of the underlying furrowed membrane (Fig. $5 E$ ), thereby allowing the meandering course and continuity of the cytoplasmic rivulets to be traced over large areas, often extending deep into the second turn of myelin. Close examination of such cytoplasmically expanded membranes revealed Cx32 gold beads beneath both E-face (Fig. $5 F$, arrow) and P-face images of gap junctions in these areas of partial compaction.

Comparison of the overall IMP densities in rivulet membranes versus nearby compact myelin revealed that rivulet membranes contained many more IMPs than compact myelin (Fig. $5 D$ ), and almost all of those IMPs were $<6 \mathrm{~nm}$ in diameter. Moreover, in rivulet E-faces, there were no large pits other than the few hexagonal clusters identified as imprints of gap junctions, and $>90 \%$ of these clusters of pits were immunogold labeled (Fig. $5 F$, arrowhead). The gap junction in Figure $5 F$, located on membrane $1_{\text {in }} \mathrm{E}$, was connected to the external membrane of an almost completely compacted rivulet in the second turn of myelin (membrane $2 \mathrm{ex}$ ). Beneath the gap junction, the remnants of successive stacked rivulets were identified on the basis of their high density of small IMPs, whereas adjacent stacks of compact smooth myelin were devoid of IMPs. Thus, gap junctions linking rivulets in the outer two turns of myelin provide direct radial pathways between the layer of partially compacted myelin and the overlying layer of noncompact myelin $(\sim 20 \mathrm{~nm})$, whereas the cytoplasm of the rivulets provides a circuitous circumferential pathway $(>10 \mu \mathrm{m})$ to the noncompacted, caveolae-rich portions of the outer tongue. On the basis of these structural differences from other areas of myelin, the continuous area between the band of tight junctions in the outer tongue of myelin and the edge of continuously compacted myelin in the second or third turn is defined as the zone of partially compact myelin (also called the area of semicompact myelin) (Mugnaini et al., 1977). The zone of partially compact myelin contains mixed areas of compact and noncompact myelin, often traversed by cytoplasmic rivulets. Many of these cytoplasmic rivulets were linked to the overlying noncompact myelin by micro gap junctions, and most of these were labeled for $\mathrm{Cx} 32$. 

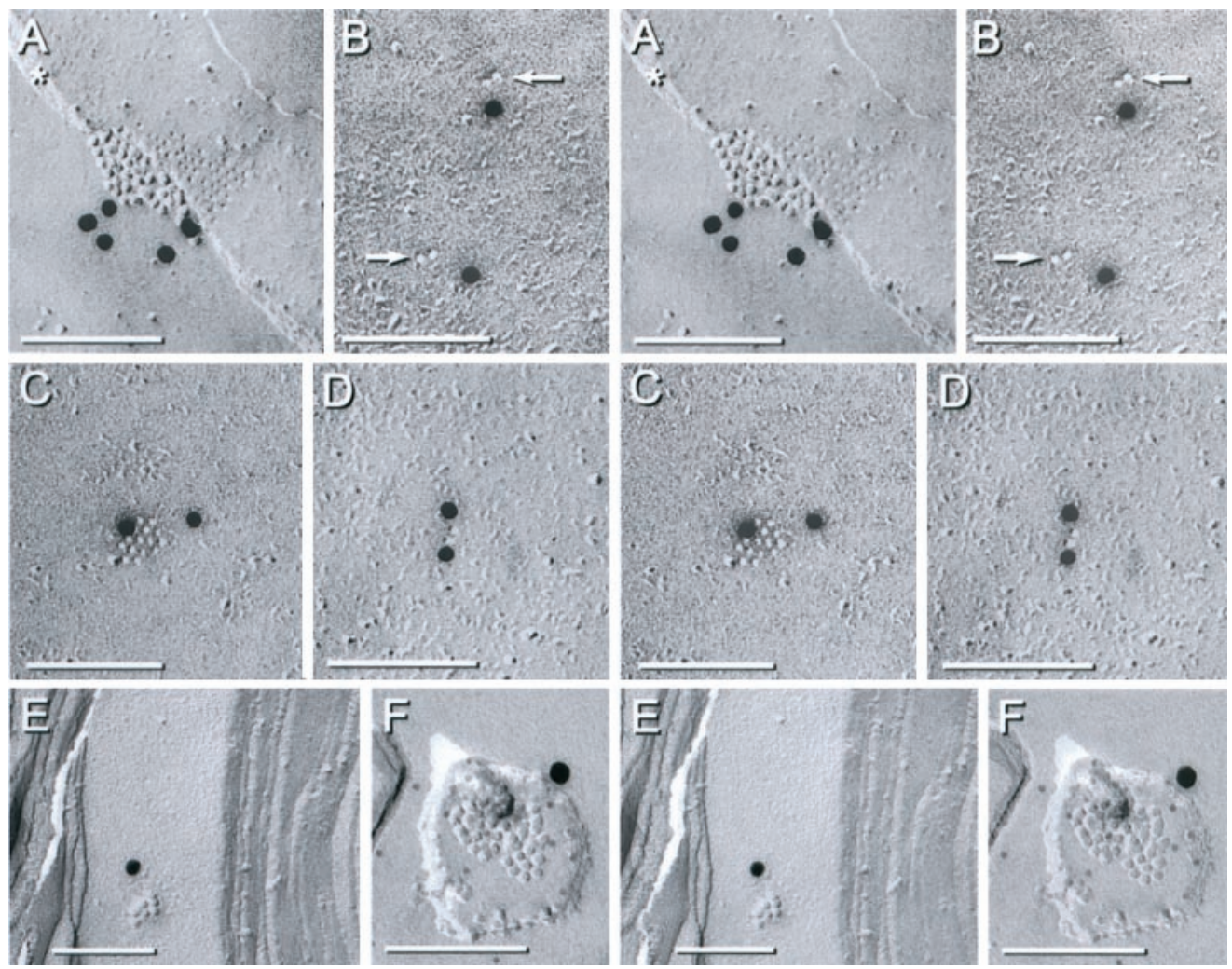

Figure 6. High-magnification FRIL images of immunogold-labeled gap junctions. $A,(\times 32-$ labeled gap junction located at the step from P-to E-face. Note the narrowing of extracellular space (*) at the area of junctional contact. B, Two gap junctions, each composed of two connexons (arrows), with each gap junction labeled by one immunogold bead. C, Gap junction composed of $15 \mathrm{E}$-face pits, labeled by two immunogold beads. D, Gap junction composed of two connexons, with $12 \mathrm{~nm}$ immunogold beads indicating the presence of $C \times 32$. E, Rare orphaned gap junction located on smooth myelin membrane deep within the stack of compact myelin. F, Gap junction at an indeterminate location in myelin. Gap junction P-face IMPs are double-labeled for CX32 by one 18 -nm and 136 -nm gold beads.

\section{Number, locations, and sizes of gap junctions in internodal myelin}

In six replicas single-labeled for $\mathrm{Cx} 32$, an estimated 500 myelinated segments and $>2000$ patches of membrane from all layers of myelin were examined for immunogold labeling. Ultimately, 152 gap junctions consisting of $\sim 1688$ connexons were found, and these were labeled by 316 immunogold beads. Some individual IMPs and pits were difficult to discern because of overlapping shadows or local defects in the shadowing film (Figs. 2C, $5 B$, respectively). Overall, we calculated a labeling efficiency (LE) of one gold bead per 5.3 connexons ( $\mathrm{LE}=1: 5.3$ ). The $\mathrm{LE}$ for $\mathrm{E}$-face pits was 1:5, and the LE for P-face connexons was 1:6. Note that labeling of $\mathrm{E}$-face pits is actually against connexins of the hemichannel of the unreplicated but intact hemiplaque of the underlying cell (Fujimoto, 1995; Rash et al., 2001). Incomplete detergent washing leaves sufficient connexins adsorbed to the platinum-carbon replica to permit essentially equal labeling of both E- and P-face images of gap junctions but, in either case, to epitopes in the cytoplasm of the underlying cell or cell process (Fujimoto, 1995; Rash and Yasumura, 1999).

Significantly, these six replicas had a signal-to-noise ratio (SNR) of 15,000:1, which is $\sim 30$ - to 50-fold higher than previously reported for CNS gap junctions (Rash and Yasumura, 1999; Rash et al., 2001; Pereda et al., 2003). (SNR is defined as the density of gold beads per square micrometer of gap junction divided by the density of gold beads per square micrometer on external plasma membranes and nuclear membranes of the same replica.) In these replicas having a high LE and very low nonspecific background, the resulting extraordinarily high SNR allowed detection of even the smallest gap junctions (Figs. 3C,D, $6 B-E$ ).
Six of these labeled gap junctions contained only two IMPs-pits (Fig. 6B,D). Such small gap junctions would not have been detected or identified by any other approach.

Gold beads were not detected near any of the few single isolated $9 \mathrm{~nm}$ IMPs, nor were loose aggregates of unlabeled $9 \mathrm{~nm}$ IMPs detected anywhere in myelin. Thus, despite extensive searches, we found no evidence for single isolated connexons or distributions consistent with aggregation or dispersal of connexons.

Overall, replicated internodal gap junctions contained an average of 11 connexons, ranging from 2 to 76 connexons (Fig. $6 A-D$ ). This largest internodal gap junction, which consisted of 36 P-face particles plus $40 \mathrm{E}$-face pits, was labeled by five gold beads (Fig. 6A). Also evident in stereoscopic images is the distinctive narrowing of the extracellular space at the area of gap junction contact (Figs. 5B, 6A). Moreover, fractures that stepped from P- to E-face within a gap junction (Fig. $6 A$ ) revealed that the apposed P-face IMPs and E-face pits were aligned across the extracellular space, supporting the notion that the connexons were assembled into intact intercellular channels. Because these gap junctions link two cytoplasmic regions within the same cell, they are considered to be reflexive or autologous (Larsen, 1983).

A total of 152 gap junctions was identified in internodal myelin, 140 of which were immunogold labeled, and 12 were unlabeled but were nevertheless identified as gap junctions on the basis of morphological criteria (Fig. $4 F$ ). Of these 152 gap junctions, 59 could not be localized to a specific membrane layer or region (i.e., to Schmidt-Lanterman incisures vs internodal myelin) (Fig. $6 \mathrm{~F}$ shows a gap junction on an isolated pedestal of 
myelin). Of the remaining 93 gap junctions that could be mapped to a particular myelin layer, 95\% (88 gap junctions) were localized to the apposition of layers $1_{\text {in }}$ and $2_{\text {ex }}$ (i.e., to the contact between the outermost and second outermost wrappings of myelin). The remaining five gap junctions were deeper within membrane stacks of compacting or compact internodal myelin (Fig. $6 E$ ). Because gap junctions were detected on the basis of their proximity to high-visibility immunogold labels, and because the search strategy included searches of all myelin layers (including much larger numbers and areas of internal myelin layers), the infrequent detection of gap junctions in deeper myelin layers suggests that $\mathrm{Cx} 32$-containing gap junctions and their constituent connexons are rarely stranded or orphaned in the deeper layers of myelin.

\section{Are other connexins expressed at internodal gap junctions?}

To investigate the possibility that the 12 unlabeled gap junctions detected in this study indicate that some gap junctions in the outer layers of internodal myelin contain connexins other than Cx32, FRIL analysis of sciatic nerves was performed using antibodies to other connexins reported to be expressed in glial cells, including Cx26, Cx29, and Cx43. Although immunogold labeling for $\mathrm{Cx} 26$ and $\mathrm{Cx} 43$ was found in gap junctions in nearby perineurial cells (data not shown), and immunogold labels to Cx29 were found in gap junctions in the innermost layers of Schwann cell myelin (Li et al., 2002; this study, data not shown), none of the other anti-connexin antibodies resulted in specific labeling of gap junctions within the outer layers of internodal myelin. Thus, these data suggest that internodal gap junctions between the outer two layers of myelin contain Cx32 but not Cx26, Cx29, or $\mathrm{Cx} 43$. However, the presence of as yet unidentified Schwann cell connexins is not excluded.

\section{Cx32 knock-out mice and the possibility of compensatory upregulation of other connexins}

To investigate further the hypothesis that internodal gap junctions are composed solely of $\mathrm{Cx} 32, \mathrm{Cx} 32$ knock-out mice were examined for the possibility of compensatory overexpression of other connexin isoforms in Schwann cells. Although Cx32deficient mice were shown previously not to express Cx32 mRNA or protein (Nelles et al., 1996), nonspecific binding of Cx32 antibodies was investigated in FRIL replicas of liver and sciatic nerve in Cx32 knock-out mice. Cx32 antibodies produced no labeling of gap junctions in myelin or liver from these animals, confirming the absence of $\mathrm{Cx} 32$ expression in knock-out mice, as well as the lack of cross-reactivity of the $\mathrm{Cx} 32$ antibodies used in this investigation. However, in the livers of $\mathrm{Cx} 32$-deficient mice, fewer and much smaller gap junctions were seen than in wildtype animals, and these remaining gap junctions were labeled for Cx26 but not Cx32 (images not shown). Thus, compensatory upregulation of $\mathrm{Cx} 26$ was not detected in the livers or myelin of Cx32 knock-out mice.

Sciatic nerves from the same knock-out mice, labeled for Cx32, Cx26, Cx29, and Cx43, were also examined for labeled and unlabeled gap junctions. Neither labeled nor unlabeled gap junctions were detected in outer myelin membranes in Cx32 nullmutant animals.

\section{Discussion}

Using FRIL and immunogold antibodies to Cx32, we found abundant but extremely small gap junctions in myelin of both young adult and mature mouse peripheral nerves. In addition to three examples of Cx32 immunogold-labeled gap junctions in
Schmidt-Lanterman incisures, we found 152 gap junctions in internodal membranes, primarily between the uncompacted outer tongue and the second layer of semicompact or partially compacted myelin.

\section{Cx32 in gap junctions at Schmidt-Lanterman incisures}

Although gap junctions have been documented in CNS myelin at paranodal loops (Sandri et al., 1977) and linking the outermost layer of myelin with adjacent astrocyte processes (Dermietzel et al., 1978; Massa and Mugnaini, 1982; Rash et al., 1997, 2001), ultrastructurally defined gap junctions have not been found previously at Schmidt-Lanterman incisures in the CNS or PNS. This study provides the first ultrastructural evidence for gap junctions at Schmidt-Lanterman incisures in PNS myelin and documents $\mathrm{Cx} 32$ in those junctions, extending previous reports from immunocytochemical and dye coupling experiments that have suggested the existence of gap junctions at that location (Spray and Dermietzel, 1995; Balice-Gordon et al., 1998; Scherer et al., 1998). Although immunostaining for $\mathrm{Cx} 32$ is also present at paranodal loops, pointing to the presence of gap junctions at these locations, neither we nor others have observed freeze-fracture evidence for gap junctions at paranodal loops in peripheral nerve myelin, primarily because of the limitations of fracturing areas with sharp membrane curvature, which occurs at Schmidt-Lanterman incisures and paranodal regions.

\section{Cx32, gap junctions, and the zone of partially compact myelin} FRIL revealed the existence and widespread distribution of gap junctions in a newly discovered expression site, between the outer two layers of internodal myelin. Moreover, these gap junctions contained Cx32 but did not contain detectable levels of Cx26, $\mathrm{Cx} 29$, or $\mathrm{Cx} 43$. The internodal gap junctions were abundant and relatively closely spaced ( $\sim 1 \mu \mathrm{m}$ apart). Although much smaller than conventional gap junctions in other tissues, averaging 11 channels per plaque, these gap junctions nevertheless represent $>22,000$ connexons (and $>132,000$ connexin molecules) per millimeter of Schwann cell myelin (calculations are based on 12 connexins per functional gap junction channel and one gap junction per micrometer). Even though $\mathrm{Cx} 32$ has been documented immunocytochemically in Schwann cells at Schmidt-Lanterman incisures and paranodal loops, the existence of Cx32-containing micro gap junctions in internodal myelin between the outer two wrappings of Schwann cell myelin was not predicted on the basis of light microscopic observations. Although gap junctions in partially compact internodal myelin are abundant, they contain too few connexins to have been detected reliably by immunofluorescence microscopy (but see Fig. $1 A$ ). In contrast, the threshold of detectability of FRIL is approximately two connexons. Similarly, analysis of dye transfer cannot, and has not, allowed separate discrimination of dye in two adjacent layers of myelin, which are not separately distinguishable because of inherent limits of resolution of light microscopy, nor can dye diffusion be resolved as occurring through the gap junctions that link two successive outer layers of internodal myelin.

Internodal gap junctions were localized to a distinctive zone that begins adjacent to the band of tight junctions that forms the diffusion barrier between the outermost and the second partially compacted wrapping of myelin and ends at the margin of continuously compact myelin. These internodal gap junctions were located primarily in membranes overlying rivulets of residual cytoplasm within a clearly demarcated zone of partially compact myelin. On the basis of established roles of gap junctions in water transport, ions and small molecules (for review, see Kumar and 


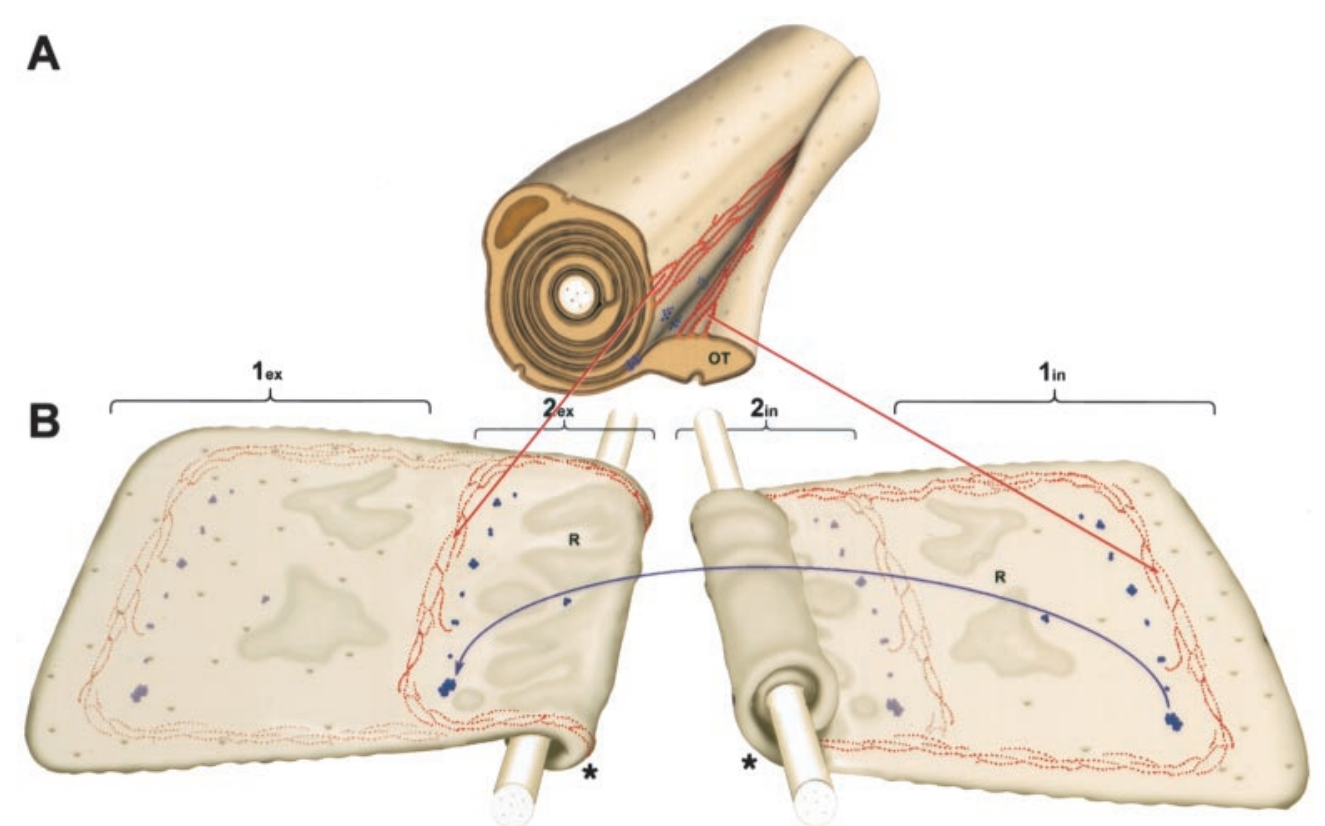

Figure 7. Diagrams of cross-sectional view versus view of unrolled outer layers of myelin in an internodal segment of peripheral nerve. $A$, Perspective view of a partially unrolled outer myelin layer, showing the outer tongue (OT) of myelin and the relative locations of tight junctions (red) and gap junctions (blue). Tight junctions and gap junctions link the inner membrane of the outer tongue to the outer membrane of the second wrapping of myelin. $B$, View of outer membrane of the first two unrolled wrappings of myelin $\left(1_{\mathrm{ex}}\right.$ and $\left.\mathrm{Z}_{\mathrm{ex}}\right)$. Tight junctions are located away from the tip of the myelin tongue a distance equal to or slightly greater than the circumference of the outermost layer of myelin $(\pi \times D)$. The pattern of tight junction strands and gap junction hemichannels in $2_{\mathrm{ex}}$ is identical to the distribution of their pairing partners in the inner surface of the first turn of the outer wrapping $\left(1_{\mathrm{in}}\right)$, as seen in the right panel of $B$. Inverted view of the same $S c h w a n n$ cell, revealing the inner membrane of the first $\left(1_{\text {in }}\right)$ and second $\left(2_{\text {in }}\right)$ Schwann cell wrappings. Few or no caveolae are present in the zone of partial compaction inside the borders of tight junctions in layer $1_{\text {in. }}$. Rivulets (R) of cytoplasm are present in the second wrapping but extend into the first wrapping, past the gap junctions, almost to the tight junctions. Additional myelin layers are not visible in this partially unrolled segment of myelin, because each successive myelin layer is wider than the previous layer, and each successive paranodal loop covers the previous loop (*).

Gilula, 1996), the abundance of gap junctions in areas where cytoplasm was markedly reduced but not eliminated suggests a role for gap junctions in direct radial transport for removal of aqueous components of cytoplasm, presumably from the areas of partial compaction in the second turn to the cytoplasmic, uncompacted, outer tongue of myelin.

The following are additional defining features of the zone of partially compact myelin. (1) In the extracellular compartment, lateral edges of the zone of myelin compaction are delineated by a continuous band of tight junctions on one side, and on the other side, by the edge of the continuously occluded extracellular space of the first continuous layer of compact myelin. (2) In the intracellular compartment, some areas are devoid of cytoplasm, whereas other areas contain meandering rivulets of cytoplasm. (3) In plasma membranes, between the tight junctions and compact myelin, gap junctions are restricted almost exclusively to the cytoplasmic patches and rivulets.

\section{Possible relevance of internodal gap junctions to myelin compaction}

In the PNS (sciatic nerve), formation of compact myelin is maximal during early postnatal development and occurs at a moderate pace from the third to the sixth month (the period from which most of our images were obtained) (Webster and Favilla, 1984; for review, see Peters et al., 1991). The zone of partially compact myelin was observed in all of our replicas, which were derived from young as well as old animals (mice 3-19 months of age), indicating that this zone is maintained throughout peripheral nerve development and maturity.

Autoradiographic studies have revealed that both lipids and proteins are added throughout the length of the forming myelinated segment, presumably by incorporation of exocytotic vesicles into the plasma membrane (Webster, 1971). Flattened membrane invaginations devoid of large IMPs and, hence, resembling remnants of fused exocytotic vesicles were found in cytoplasmic myelin in the zone of partial compaction. These invaginations may represent areas of recent addition of membrane characteristic of mature myelin, as suggested by Mugnaini et al. (1977). Moreover, those myelin components appear to be added as particle-free membrane patches, thus resembling preformed compact myelin within the zone of semicompact myelin (Mugnaini et al., 1977). The maintenance of the zone of partial compaction throughout life might therefore point to its functional relevance. However, analyzing the mechanisms and sites of myelin compaction is outside the scope of this FRIL characterization of newly discovered gap junctions in internodal myelin. Nevertheless, we call attention to the various ultrastructural components present in the outer two turns of myelin. A summary diagram (Fig. 7) illustrates the layers of myelin and the location of gap junctions with respect to exocytotic vesicles, tight junctions, cytoplasmic ridges, and the transition zone between noncompact and compact myelin. The drawing also reveals that the gap junctions and tight junctions on layer $2_{\mathrm{ex}}$ are precise mirror images of gap junctions and tight junctions on layer $1_{\text {in }}$.

\section{Differential distribution of Cx32 and Cx29}

On the basis of light microscopic evidence, the majority of detectable Cx32 and Cx29 immunoreactivity was reported to be present within Schmidt-Lanterman incisures and paranodal loops (Altevogt et al., 2002; Li et al., 2002). However, investigations of the subcellular distribution of these connexins at the electron microscopic level revealed Cx32 and Cx29 at additional sites. By FRIL, Cx32 was found to be concentrated in gap junctions of the nuclear (abaxonal) end of the myelin (this study), whereas Cx29 was 
found to be concentrated in the adaxonal end (Li et al., 2002). The assymetric subcellular distributions of Cx32 and Cx29 imply that connexins with different properties are required at different subcellular locations, and that there are functional differences in the apical and basal Schwann cell compartments. These functional differences may be related to $\mathrm{Cx} 32$-specific activity in the outer layers of myelin versus an unidentified function for Cx29 in the innermost layer of myelin ( Li et al., 2002).

\section{Gap junctions as conduits for water and ions}

Although Cx32-containing gap junctions in internodal myelin contain an average of only 11 connexons, the abundance of these junctions may provide sufficient numbers of well distributed channels for the efficient radial transport of water, ions, and small molecules between the partially compact layer and the noncompacted outer tongue. Moreover, the near absence of gap junctions (and very low density of dispersed $10 \mathrm{~nm}$ IMPs and absence of gold labels for $\mathrm{Cx} 32$ ) in more inward layers of compact myelin implies that $\mathrm{Cx} 32$-containing gap junctions are not present and, hence, not required at these other subcellular sites. Moreover, the rarity of gap junctions in deeper layers suggests the existence of an efficient but fallible mechanism for removing connexons from compacting layers before complete compaction. However, once stranded within deeper myelin layers, absence of cytoplasm may prevent endocytosis and recycling of the few remaining orphaned gap junctions. Finally, the near absence of gap junctions in deeper layers indicates that there is little or no lateral movement of connexons into compact myelin.

\section{Relevance of internodal gap junctions to human neurological disease}

Mice with a null mutation in the $\mathrm{Cx} 32$ gene have myelinated axons, albeit with distinctive abnormalities, leading to the hypothesis that $\mathrm{Cx} 32$ is not required for myelin formation or compaction per se (Nelles et al., 1996; Anzini et al., 1997; Scherer et al., 1998). However, "severe structural abnormalities," including "abnormally organized noncompacted aspects of myelinating Schwann cells," have been reported in myelin sheaths of these mice (Anzini et al., 1997). The current demonstration of Cx32 in a newly discovered internodal expression site for gap junctions, as well as in gap junctions at Schmidt-Lanterman incisures, suggests a functional role for $\mathrm{Cx} 32$ at these locations. In myelin sheaths of Cx32-deficient mice labeled for Cx32, Cx26, Cx29, and $\mathrm{Cx} 43$, neither labeled nor unlabeled gap junctions were detected in outer myelin membranes, indicating either the lack of compensatory expression of any other connexins between the outer two layers of internodal myelin or our inability to find them by FRIL because of the presence of connexins other than those tested. In that regard, the expression of other connexins at Schmidt-Lanterman incisures has been predicted on the basis of dye transfer studies (Balice-Gordon et al., 1998). Schwann cell connexins other than Cx32 might include Cx29 and Cx43, and their expression at Schmidt-Lanterman incisures has not been ruled out by this study.

Deletion of $\mathrm{Cx} 32$ resulted in the absence of detectable gap junctions in internodal myelin (this study). Absence of otherwise abundant internodal gap junctions would be predicted to result in altered water and ion homeostasis in the zone of partially compact myelin, which may provide a partial explanation for the deleterious alterations in the CMT-X neuropathy. Because substantial myelin compaction occurs in the absence of gap junctions in Cx32-deficient mice (Scherer et al., 1998), Cx32-containing gap junctions appear not to be required for compaction per se.
Nevertheless, the abundance and regular distribution of internodal gap junctions in normal animals (this study) is consistent with an essential role for these junctions in the unidirectional or bidirectional interlamellar transport of water and ions between the two outer layers of myelin, possibly for the process of myelin compaction or maintaining the border of compact myelin at the transition zone between compacted and noncompact myelin.

\section{References}

Altevogt BM, Kleopa KA, Postma FR, Scherer SS, Paul DL (2002) Connexin29 is uniquely distributed within myelinating glial cells of the central and peripheral nervous systems. J Neurosci 22:6458-6470.

Anzini P, Neuberg DH, Schachner M, Nelles E, Willecke K, Zielasek J, Toyka KV, Suter U, Martini R (1997) Structural abnormalities and deficient maintenance of peripheral nerve myelin in mice lacking the gap junction protein connexin 32. J Neurosci 17:4545-4551.

Balice-Gordon RJ, Bone LJ, Scherer SS (1998) Functional gap junctions in the Schwann cell myelin sheath. J Cell Biol 142:1095-1104.

Bergoffen J, Scherer SS, Wang S, Oronzi-Scott M, Bone L, Paul DL, Chen K, Lensch MW, Chance P, Fischbeck K (1993) Connexin mutations in X-linked Charcot-Marie-Tooth disease. Science 262:2039-2042.

Branton D, Bullivant S, Gilula NB, Karnovsky MJ, Moor H, Muhlethaler K, Northcote DH, Packer L, Satir B, Satir P, Speth V, Staehlin LA, Steere RL, Weinstein RS (1975) Freeze-etching nomenclature. Science 190:54-56.

Bunge MB, Bunge RP, Cochran ER (1978) Some factors influencing the proliferation and differentiation of myelin forming cells. Neurology 9:59-67.

Chandross KJ, Kessler JA, Cohen RI, Simburger E, Spray DC, Bieri P, Dermietzel R (1996) Altered connexin expression after peripheral nerve injury. Mol Cell Neurosci 7:501-518.

Chen YA, Scheller RH (2001) SNARE-mediated membrane fusion. Nat Rev Mol Cell Biol 2:98-106.

Dermietzel R, Schuenke D, Leibstein A (1978) The oligodendrocytic junctional complex. Cell Tiss Res 193:61-72.

Dinchuk JE, Johnson TJ, Rash JE (1987) Postreplication labeling of E-leaflet molecules: membrane immunoglobulins localized in sectioned, labeled replicas examined by TEM and HVEM. J Electron Microsc Tech 7:1-16.

Fujimoto K (1995) Freeze-fracture replica electron microscopy combined with SDS digestion for cytochemical labelling of integral membrane proteins. Application to the immunogold labelling of intercellular junctional complexes. J Cell Science 108:3443-3449.

Goodenough DA (1975) Methods for the isolation of and structural characterization of hepatocyte gap junctions. In: Methods in membrane biology, Chap 2, Vol III (Korn ED, ed), pp 51-80. New York: Plenum.

Kumar NM, Gilula N (1996) The gap junction communication channel. Cell 84:381-388.

Larsen WJ (1983) Biological implications of gap junction structure, distribution and composition: a review. Tissue Cell 15:645-671.

Li X, Lynn BD, Olson C, Meier C, Davidson KG, Yasumura T, Rash JE, Nagy JI (2002) Connexin29 expression, immunocytochemistry and freezefracture replica immunogold labelling (FRIL) in sciatic nerve. Eur J Neurosci 16:795-806.

Mambetisaeva ET, Gire V, Evans WH (1999) Multiple connexin expression in peripheral nerve, Schwann cells, and Schwannoma cells. J Neurosci Res 57:166-175.

Martini R, Schachner M (1997) Molecular bases of myelin formation as revealed by investigations on mice deficient in glial cell surface molecules. Glia 19:298-310.

Massa PT, Mugnaini E (1982) Cell junctions and intramembrane particles of astrocytes and oligodendrocytes: a freeze-fracture study. Neuroscience 7:523-538.

Mugnaini E, Osen KK, Schnapp B, Friedrich Jr VL (1977) Distribution of Schwann cell cytoplasm and plasmalemmal vesicles (caveolae) in peripheral myelin sheaths. An electron microscopic study with thin sections and freeze-fracturing. J Neurocytology 6:647-668.

Nagaoka T, Oyamada M, Okajima S, Takamatsu T (1999) Differential expression of gap junction proteins connexin26, 32, and 43 in normal and crush-injured rat sciatic nerves. Close relationship between connexin 43 and occludin in the perineurium. J Histochem Cytochem 47:937-948.

Nelles E, Butzler C, Jung D, Temme A, Gabreil HD, Dahl U, Traub O, Stumpel F, Jungermann K, Zielasek J, Toyka K, Dermietzel R, Willecke K (1996) 
Defective propagation of signals generated by sympathetic nerve stimulation in the liver of connexin32-deficient mice. Proc Natl Acad Sci USA 93:9565-9570.

Pereda A, O’Brien J, Nagy JI, Bukauskas F, Davidson KGV, Yasumura T, Rash J (2003) Connexin 35 mediates electrical transmission at mixed synapses on Mauthner cells. J Neurosci 23:7489-7503.

Peters A, Palay SL, Webster HD (1991) The fine structure of the nervous system. Neurons and their supporting cells, Ed 3, pp 212-272. Oxford: Oxford UP.

Phillips TE, Boyne AF (1984) Liquid nitrogen-based quick freezing: experiments with bounce-free delivery of cholinergic nerve terminals to a metal surface. J Electron Micros Res 1:9-29.

Rash JE, Yasumura T (1999) Direct immunogold labeling of connexins and aquaporin-4 in freeze-fracture replicas of liver, brain, and spinal cord: factors limiting quantitative analysis. Cell Tiss Res 296:307-321.

Rash JE, Johnson TJA, Dinchuk JE, Duch DS, Levinson SR (1990) Labeling intramembrane particles in freeze-fracture replicas. In: Freeze-fracture studies of membranes (Hui SW, ed), pp 41-59. Boca Raton: CRC.

Rash JE, Dillman RK, Morita M, Whalen LR, Guthrie PB, Fay-Guthrie D (1995) Grid-mapped freeze fracture: correlative confocal laser scanning microscopy and freeze-fracture electron microscopy of preselected cells in tissue slices. In: Rapid freezing, freeze fracture, deep etching (Severs NJ, Shotton DM, eds), pp 127-150. New York: Wiley-Liss.

Rash JE, Duffy HS, Dudek FE, Bilhartz BL, Whalen LR, Yasumura T (1997) Grid-mapped freeze-fracture analysis of gap junctions in gray and white matter of adult rat central nervous system, with evidence for a "panglial syncytium" that is not coupled to neurons. J Comp Neurol 388:265-292.

Rash JE, Yasumura T, Hudson CS, Agre P, Nielsen S (1998) Direct immunogold labeling of aquaporin- 4 in square arrays of astrocyte and ependymocyte plasma membranes in rat brain and spinal cord. Proc Natl Acad Sci USA 95:11981-11986.

Rash JE, Yasumura T, Dudek FE, Nagy JI (2001) Cell-specific expression of connexins and evidence of restricted gap junctional coupling between glial cells and between neurons. J Neurosci 21:1983-2000.
Sandri C, Van Buren JM, Akert K (1977) Membrane morphology of the vertebrate nervous system. Prog Brain Res 46:201-265.

Scherer SS, Deschênes SM, Xu Y-T, Grinspan JB, Fischbeck K, Paul DL (1995) Connexin 32 is a myelin-related protein in the PNS and CNS. J Neurosci 15:8281-8294.

Scherer SS, Xu Y-T, Nelles E, Fischbeck K, Willecke K, Bone LJ (1998) Connexin 32 null-mutant mice develop a demyelinating peripheral neuropathy. Glia 24:8-20.

Smart EJ, Graf GA, McNiven MA, Sessa WC, Engelman JA, Scherer PE, Okamoto T, Lisanti MP (1999) Caveolins, liquid-ordered domains, and signal transduction. Mol Cell Biol 19:7289-7304.

Spray DC, Dermietzel R (1995) X-linked dominant Charcot-Marie-Tooth disease and other potential gap junction diseases of the nervous system. Trends Neurosci 18:256-262.

Staehelin LA (1974) Structure and function of intercellular junctions. Internat Rev Cytol 39:191-283.

Steere RL, Erbe EF, Moseley JM (1980) Prefracture and cold-fracture images of yeast plasma membranes. J Cell Biol 86:113-122.

Tetzlaff W (1982) Tight junction contact events and temporary gap junctions in the sciatic nerve fibres of the chicken during Wallerian degeneration and subsequent regeneration. J Neurocytol 11:839-858.

Webster HD (1971) The geometry of peripheral myelin sheaths during their formation and growth in rat sciatic nerves. J Cell Biol 48:348-367.

Webster HD, Favilla JT (1984) Development of peripheral nerve fibers. In: Peripheral neuropathy (Dyck JP, Thomas PK, Lambert EH, Bunge R, eds), Vol I, Ch 15, pp 329-359. Philadelphia: Saunders.

Winkler H, Wildhaber H, Gross H (2002) Decoration on the surface of a regular protein layer. Ultramicroscopy 16:331-339.

Yoshimura T, Satake M, Kobayashi T (1996) Connexin43 is another gap junction protein in the peripheral nervous system. J Neurochem 67:1252-1258.

Zhao S, Fort A, Spray DC (1999) Characteristics of gap junction channels in Schwann cells from wild-type and connexin-null mice. Ann NY Acad Sci 883:533-537. 